\title{
Improving efficiency and stability of perovskite solar cells with photocurable fluoropolymers
}

\author{
Federico Bella, ${ }^{1 *+}$ Gianmarco Griffini, ${ }^{2 *+}$ Juan-Pablo Correa-Baena,${ }^{3+}$ Guido Saracco, ${ }^{4}$ Michael Grätzel, ${ }^{5}$ \\ Anders Hagfeldt, ${ }^{3 *}$ Stefano Turri, ${ }^{2}$ Claudio Gerbaldi ${ }^{1}$
}

${ }^{1}$ GAME Lab, CHENERGY Group, Department of Applied Science and Technology, DISAT, Politecnico di Torino, Corso Duca degli Abruzzi 24, 10129, Torino, Italy. ${ }^{2}$ Department of Chemistry, Materials and Chemical Engineering "Giulio Natta," Politecnico di Milano, Piazza Leonardo da Vinci 32, 20133, Milano, Italy. . 2 Laboratory of Photomolecular Science, Institute of Chemical Sciences and Engineering, Ecole Polytechnique Fédérale de Lausanne (EPFL), Chemin des Alambics, Station 3, 1015, Lausanne, Switzerland. ${ }^{4}$ Center for Sustainable Futures @Polito, Istituto Italiano di Tecnologia, Corso Trento 21, 10129, Torino, Italy. 5 Laboratory of Photonics and Interfaces, Institut des Sciences et Ingénierie Chimiques, Ecole Polytechnique Fédérale de Lausanne (EPFL), Station 3, 1015, Lausanne, Switzerland.

*Corresponding author. Email: federico.bella@polito.it (F.B.); gianmarco.griffini@polimi.it (G.G.); anders.hagfeldt@epfl.ch (A.H.)

tThese authors contributed equally to this work.

Organometal halide perovskite solar cells have demonstrated high conversion efficiency but poor longterm stability against ultraviolet irradiation and water. We show that rapid light-induced free-radical polymerization at ambient temperature produces multifunctional fluorinated photopolymer coatings that confer luminescent and easy-cleaning features on the front side of the devices, while concurrently forming a strongly hydrophobic barrier toward environmental moisture on the back contact side. The luminescent photopolymers re-emit ultraviolet light in the visible range, boosting perovskite solar cells efficiency to nearly $19 \%$ under standard illumination. Coated devices reproducibly retain their full functional performance during prolonged operation, even after a series of severe aging tests carried out for more than 6 months.

Photovoltaic devices made with organometal halide perovskites (perovskite solar cells, or PSCs) have achieved certified power conversion efficiencies (PCE) as high as $22.1 \%$ (1-9). Reliable device operation will require achieving longterm stability (10-12), in which PSCs suffer from two types of stresses that severely limit their operation, namely degradation from atmospheric exposure and electrical stresses (polarization). The latter is represented by a hysteresis loop in current-voltage measurement under light, and is caused by ionic motion in the perovskite material that can be overcome largely by using appropriate contacts (13) or modifying morphology (14). However, the stability of PSCs in humid environments, where also photochemical and thermal stresses are typically encountered, have presented an unsurmountable challenge to date $(11,12)$.

Several strategies to improve the stability of PSCs have been proposed. Device encapsulation, where hydrophobic polymer layers may substantially limit the permeation of atmospheric moisture $(15,16)$, is not suitable for protecting the device against photochemical and thermal stresses during outdoor functioning. Replacement (or protection) of the organic components with metal oxides, e.g., a chromium oxide-chromium $\left(\mathrm{Cr}_{2} \mathrm{O}_{3} / \mathrm{Cr}\right)$ interlayer protecting the metal contacts from reactions with the perovskite material, has recently been proposed, as well as the fabrication of solar cells with all-solution-processed metal oxide charge transport layers (17-19). However, these strategies [and oth- ers, such as the perovskite crystal cross-linking with alkylphosphonic acid $\omega$-ammonium chlorides $(20)$ or the introduction of porous carbon layers $(21,22)]$ impact only the air-stability of the solar cells. With regard to ultraviolet (UV)-light stability, cesium bromide has been recently proposed as interfacial modifier between the electron collection layer and the perovskite absorber layer, but resistance to moisture or high temperatures remains to be demonstrated (23).

We propose the use of multifunctional photopolymers as a comprehensive promising solution to PSC instability. A luminescent downshifting (LDS) fluoropolymeric layer is rapidly photogenerated on the front side of the device (i.e., glass-side), as detailed in section 1 in the supplementary materials (24). The coating prevents the UV portion of the incident solar spectrum to negatively interact with the PSC stack by converting it into visible light (Fig. 1A), and also increases the photocurrent by $6 \%$. Devices can achieve PCEs approaching $19 \%$ without affecting the chemistry as well as the electronic properties of both the photoactive and the buffer layers. With regards to atmospheric humidity tolerance, a strongly hydrophobic photopolymer is grown on the back contact side. This additional layer behaves as an efficient barrier toward water permeation within the solar cell stack. The resulting devices demonstrated unrivalled stability in terms of PCEs during a 180-day (4320 hours) aging test carried out under different atmospheric conditions and 
in the presence of various photochemical external stresses. The same devices were also exposed to real outdoor conditions for more than 3 months (2160 hours), successfully demonstrating their exceptional tolerance to dust, soil and heavy rain on the external glass surface. Finally, the lowsurface-energy fluorinated LDS layer makes the front electrode easily cleanable in real outdoor conditions.

The precursor material used for the LDS coatings is based on a combination of a UV-curable chloro-trifluoroethylene vinyl ether fluoropolymer binder and a dimethacrylic perfluoropolyether oligomer. The materials react upon UV-light exposure to give a fully cross-linked coating (full characterization of the coating material is presented in sections 2 to 4 in the supplementary materials) (25). In order to impart the LDS functionality to this fluoropolymeric coating (referred to as "UV-coating" hereafter), a luminescent species was added to the precursor formulation in different amounts. The fluorescent organic dye Lumogen F Violet 570 by BASF (from now on referred to as V570, see inset of fig. S2D) was selected as a luminophore given its commercial availability and favorable optical properties (i.e., high absorption coefficient and fluorescence quantum yield) (26). In addition, this particular class of dyes is characterized by relatively good solubility in the polymer to avoid aggregation-induced quenching and easy processability in polymers (26).

The optical properties of the V570-doped fluoropolymeric coating are well matched with the spectral response of the PSC devices we used (Fig. 1B). In particular, the absorption spectrum of the LDS material peaks in the shortwavelength region where the PSC device exhibits a minimum incident photon-to-current conversion efficiency (IPCE) $\left[\lambda_{\max }(\mathrm{abs})=377 \mathrm{~nm}\right]$. As a result of the fluorescence process (Fig. 1D), the re-emitted photons are red-shifted to a region where the IPCE of the device is maximum.

We tested these films on devices composed of a typical stack of $\mathrm{FTO} /$ compact- $\mathrm{TiO}_{2} /$ mesoporous- $\mathrm{TiO}_{2} /$ mixed perovskite/spiro-OMeTAD/gold (Fig. 1C). The compact-TiO ${ }_{2}$ and thin mesoporous- $\mathrm{TiO}_{2}$ layers are used as the electron selective materials, while the perovskite capping layer absorbs most of the light and transports the charges. Spiro-OMeTAD is used as the hole selective layer. In this study, a Pb-based "mixed" perovskite containing a mix of cations and halides (formamidinium iodide: $\mathrm{PbI}_{2}$ : methylammonium bromide: $\left.\mathrm{PbBr}_{2}=1.0: 1.1: 0.20: 0.22\right)$ is used, as described in our recent publications $(27,28)$ and detailed in the experimental section. Thin films of liquid, light-curable reactive mixtures (precursors of the fluoropolymeric layer) with different amounts of V570 were spin-coated on the front side of the devices. Then, the as-cast wet fluoropolymeric precursor was UV-irradiated for $30 \mathrm{~s}$ under a nitrogen atmosphere to cure a layer $\sim 5 \mu \mathrm{m}$ in thickness.
The photovoltaic response of the resulting PSCs at increasing V570 concentration is shown in Table 1, where the efficiency-boosting effect of the LDS coatings on device performance can be noted for V570 loadings in the range of 1 to $2 \mathrm{wt} \%$. The short circuit photocurrent density $\left(J_{\mathrm{sc}}\right)$ increased from 19.20 to $20.31 \mathrm{~mA} \mathrm{~cm}^{-2}$ when $2 \mathrm{wt} \%$ of V570 was introduced in the fluorinated coating, thus leading to a $6 \%$ increase in $J_{\mathrm{sc}}$ (and also in PCE). At higher fluorophore loadings ( $>2 \mathrm{wt} \%$ ), the photocurrent density started to decrease, likely because a greater amount of fluorescent species can reasonably increase the probability for an emitted photon to be reabsorbed by another adjacent fluorophore molecule within the polymeric layer, given the partial overlap between absorption and emission bands of V570 (Fig. 1B and fig. S1D). For V570 loadings exceeding $3 \mathrm{wt} \%$ the $J_{\mathrm{sc}}$ values were further lowered.

In order to confirm the beneficial effects of the LDS coatings on the photocurrent generated upon illumination, IPCE curves were recorded (Fig. 2A). The luminescent species introduced in the polymeric architecture effectively converted the near-UV region of the solar spectrum (Fig. 2B) into lower-energy photons of wavelengths well matching the absorption spectrum of the perovskite layer.

These PSCs have relatively moderate but highly reproducible efficiencies $(\approx 15.5 \%)$. We also investigated the LDS effect with more efficient devices (PCE $>17 \%$ ) by incorporating an optimized LDS coating (i.e., fluorophore concentration of $2 \mathrm{wt} \%$ ). The increase in PCE from 17.31 to $18.67 \%$ resulted from a $\approx 5 \%$ enhancement in photocurrent ( $J_{\mathrm{sc}}$ increased from 21.96 to $23.23 \mathrm{~mA} \mathrm{~cm}{ }^{-2}$ ). Given the correlation between $J_{\text {sc }}$ and V570 content (Table 1) and the broadening of the IPCE curve in the UV region (see Fig. 2B), we can exclude that such photocurrent enhancement is caused by a mere antireflective effect produced by the LDS layer (as also confirmed by the poorer performance observed on the undoped LDS system). Conversely, the downshifting phenomenon consistently explains the measured trends. The integration of the product of the AM1.5G photon flux with the IPCE spectrum (Fig. 3B) yielded predicted $J_{\text {sc }}$ values equal to 21.09 and $22.13 \mathrm{~mA} \mathrm{~cm}{ }^{-2}$ for the uncoated and coated devices, respectively; the mismatch with respect to the values inferred from the $J-V$ curves (Fig. $3 \mathrm{~A}$ ) was equal to $\approx 1$ $\mathrm{mA} \mathrm{cm}{ }^{-2}$, consistently with other recent reports in the PSC field $(21,29,30)$. The excellent quality of the fabricated PSCs is reflected in the negligible hysteresis phenomenon observed in the $J-V$ curves of our high-efficiency devices (Fig. $3 \mathrm{~A}$, dotted lines), consistently with recent reports (14).

We tested whether these luminescent polymeric coatings (with 2 wt\% loading) can enhance device stability on a longterm basis, by carrying out three aging studies under markedly different conditions. In the first aging test, uncoated devices and front-coated ones (five solar cells for each con- 
dition) were studied for an overall period of 6 months. In the first 3 months, the devices were kept in an Ar-filled dry glove box and continuously irradiated ( 8 hours per day) with a UV optical fiber having a $5 \mathrm{~mW} \mathrm{~cm} \mathrm{~cm}^{-2}$ intensity. This value simulates well the $5 \%$ contribution given by UV light (280 to $400 \mathrm{~nm}$ ) to the overall solar spectral irradiance on Earth (1000 W m ${ }^{-2}$, AM1.5G) based on the Standard Reference Solar Spectra (ASTM G-173-03). The uncoated devices (black curve) in this UV-induced aging test (Fig. 4A) lost $30 \%$ of their initial efficiency after 1 week of exposure and failed after 1 month; conversely, all five front-coated cells (red curve) demonstrated excellent stability under the same conditions, retaining $98 \%$ of their initial PCE after 3 months.

After this period, the solar cells were taken out of the Arfilled glove box and placed inside a quartz chamber, where they were exposed to constant relative humidity (50\%), and the aging test was allowed to proceed in the same UV irradiation conditions described above. Figure 4A shows that, immediately after the modification of the aging conditions, front-coated cells (red curve) showed a sharp decrease in efficiency, resulting in an $82 \%$ decrease of their initial efficiency at the end of the second quarter of the aging test. Such a rapid decay was attributed to the amount of moisture present in the aging chamber that progressively infiltrated the PSC stack from the back contact side, thus causing the gradual hydrolysis of the perovskite layer. The effects of degradation were easily detectable by simple visual inspection, as a progressive yellowing of the mixedperovskite layer upon $50 \% \mathrm{RH}$ exposure was observed (see inset of Fig. 4A).

With the aim of stabilizing our devices in terms of photochemical resistance as well as moisture tolerance, a fluoropolymeric light-curable coating was deposited also on the back contact side (front/back-coated device configuration). The same formulation used in the LDS experiment was used for back coating the PSC devices, except that no luminescent dye was used. The use of such fluoropolymeric layer on top of the PSC stack is expected to efficiently combat water permeation through the top back contact toward the perovskite layer as a result of the highly hydrophobic character of the coating (see section 3 in the supplementary materials) (25). In addition, the cross-linked nature of the fluoropolymeric UV-coating entails a lower free volume than typical non-cross-linked polymeric systems and should therefore enhance the long-term durability of PSCs $(31,32)$.

Figure 4A shows the aging test performed onto front/back-coated PSCs (blue curve), viz. devices bearing the luminescent coating on the front side and the moistureresistant one on the back contact side. All of the five devices maintained an excellent stability (98\%) in the aging conditions resulting from the combined effects of photochemical and environmental stresses. X-ray diffraction (XRD) (Fig. 4B) analysis showed that performance degradation corresponded to the decomposition of the crystalline perovskite material into $\mathrm{PbI}_{2}$, which was not observed for the fully coated devices (see section 6 in the supplementary materials).

Given the stabilizing effect of the fluoropolymeric coating applied on both sides of the cells, a second aging test was designed to verify the stability of the front/back-coated PSCs under real outdoor atmospheric conditions, where temperature variations, precipitation phenomena and pollution are typically encountered. A batch of five cells was exposed on the terrace of the Politecnico di Torino building in Turin $\left(45^{\circ} 06^{\prime} \mathrm{N}, 7^{\circ} 66^{\prime} \mathrm{E}\right)$, located in northwest Italy in a humid subtropical climate zone from October to December 2015. The PSCs were subjected to highly variable climatic conditions, as outdoor temperatures ranged from -3 to $+27^{\circ} \mathrm{C}$, and 27 days over 92 were characterized by heavy rain and storms (33), as shown in Fig. 4C. The front/back-coated PSCs exhibited long-term stability retaining $95 \%$ of their initial efficiency after this test by: (i) protecting the perovskite from UV-radiation, converting it into exploitable visible photons; (ii) acting as a moisture barrier, thus preventing hydrolytic phenomena of the perovskite material; and (iii) keeping the front electrode clean by means of the self-cleaning characteristics of this fluorinated polymer. Similar results were found for tests performed during Summer 2016, and the data collected are available in section 7 in the supplementary materials.

To demonstrate the water resistance of the photopolymerized fluorinated coatings, we kept five solar cells for 1 month in a closed chamber in the presence of a beaker containing boiling water (95\% RH, fig. S1C), and the photovoltaic response was evaluated once a week. After 1 month, four of the five cells withstood the strong aging conditions and remarkably retained $96 \pm 2 \%$ of their initial PCE. Only one device lost $95 \%$ of its initial efficiency after the first week. After inspection, we found a small area on the back side of the solar cell not thoroughly coated by the fluoropolymeric layer. The nonhomogeneous deposition of the coating caused a gradual hydrolysis of the underlying perovskite layer. We also dipped the front/back-coated devices into water. After 1 day of immersion, no changes in their photovoltaic performance were observed.

\section{REFERENCES AND NOTES}

1. H. S. Kim, C. R. Lee, J. H. Im, K. B. Lee, T. Moehl, A. Marchioro, S. J. Moon, R. Humphry-Baker, J. H. Yum, J. E. Moser, M. Grätzel, N. G. Park, Lead iodide perovskite sensitized all-solid-state submicron thin film mesoscopic solar cell with efficiency exceeding 9\%. Sci. Rep. 2, 591 (2012)

2. M. M. Lee, J. Teuscher, T. Miyasaka, T. N. Murakami, H. J. Snaith, Efficient hybrid solar cells based on meso-superstructured organometal halide perovskites. Science 338, 643-647 (2012).doi:10.1126/science.1228604 Medline 
3. H. Zhou, Q. Chen, G. Li, S. Luo, T. B. Song, H. S. Duan, Z. Hong, J. You, Y. Liu, Y. Yang, Interface engineering of highly efficient perovskite solar cells. Science 345 , 542-546 (2014).doi:10.1126/science.1254050 Medline

4. M. Liu, M. B. Johnston, H. J. Snaith, Efficient planar heterojunction perovskite solar cells by vapour deposition. Nature 501, 395-398 (2013).doi:10.1038/nature12509 Medline

5. J. Burschka, N. Pellet, S. J. Moon, R. Humphry-Baker, P. Gao, M. K. Nazeeruddin, M. Grätzel, Sequential deposition as a route to high-performance perovskitesensitized solar cells. Nature 499, 316-319 (2013).doi:10.1038/nature12340 Medline

6. National Center for Photovoltaics (NCPV) at the National Renewable Energy Laboratory (NREL); http://www.nrel.gov/ncpv (accessed July 2016).

7. N. G. Park, Perovskite solar cells: An emerging photovoltaic technology. Mater. Today 18, 65-72 (2015). doi:10.1016/i.mattod.2014.07.007

8. J. Seo, J. H. Noh, S. I. Seok, Rational strategies for efficient perovskite solar cells. Acc. Chem. Res. 49, 562-572 (2016).doi:10.1021/acs.accounts.5b00444 Medline

9. H. S. Jung, N. G. Park, Perovskite solar cells: From materials to devices. Small 11, 10-25 (2015).doi:10.1002/smll.201402767 Medline

10. T. A. Berhe, W. N. Su, C. H. Chen, C. J. Pan, J. H. Cheng, H. M. Chen, M. C. Tsai, L. Y. Chen, A. A. Dubale, B. J. Hwang, Organometal halide perovskite solar cells: Degradation and stability. Energy Environ. Sci. 9, 323-356 (2016). doi:10.1039/C5EE02733K

11. Y. Rong, L. Liu, A. Mei, X. Li, H. Han, Beyond efficiency: The challenge of stability in mesoscopic perovskite solar cells. Adv. Energy Mater. 5, 1501066 (2015). doi:10.1002/aenm.201501066

12. T. Leijtens, G. E. Eperon, N. K. Noel, S. N. Habisreutinger, A. Petrozza, H. J. Snaith, Stability of metal halide perovskite solar cells. Adv. Energy Mater. 5, 1500963 (2015). doi:10.1002/aenm.201500963

13. J. P. Correa Baena, L. Steier, W. Tress, M. Saliba, S. Neutzner, T. Matsui, F. Giordano, T. J. Jacobsson, A. R. Srimath Kandada, S. M. Zakeeruddin, A. Petrozza, A. Abate, M. K. Nazeeruddin, M. Grätzel, A. Hagfeldt, Highly efficient planar perovskite solar cells through band alignment engineering. Energy Environ. Sci. 8, 2928-2934 (2015). doi:10.1039/C5EE02608C

14. J. P. Correa-Baena, M. Anaya, G. Lozano, W. Tress, K. Domanski, M. Saliba, T. Matsui, T. J. Jacobsson, M. E. Calvo, A. Abate, M. Grätzel, H. Míguez, A. Hagfeldt, Unbroken perovskite: Interplay of morphology, electro-optical properties, and ionic movement. Adv. Mater. 28, 5031-5037 (2016).doi:10.1002/adma.201600624 Medline

15. H. C. Weerasinghe, Y. Dkhissi, A. D. Scully, R. A. Caruso, Y. B. Cheng, Encapsulation for improving the lifetime of flexible perovskite solar cells. Nano Energy 18, 118-125 (2015). doi:10.1016/i.nanoen.2015.10.006

16. I. Hwang, I. Jeong, J. Lee, M. J. Ko, K. Yong, Enhancing stability of perovskite solar cells to moisture by the facile hydrophobic passivation. ACS Appl. Mater. Interfaces 7, 17330-17336 (2015).doi:10.1021/acsami.5b04490 Medline

17. M. Kaltenbrunner, G. Adam, E. D. Głowacki, M. Drack, R. Schwödiauer, L. Leonat, D. H. Apaydin, H. Groiss, M. C. Scharber, M. S. White, N. S. Sariciftci, S. Bauer, Flexible high power-per-weight perovskite solar cells with chromium oxide-metal contacts for improved stability in air. Nat. Mater. 14, 1032-1039 (2015).doi:10.1038/nmat4388 Medline

18. J. You, L. Meng, T.-B. Song, T.-F. Guo, Y. M. Yang, W.-H. Chang, Z. Hong, H. Chen, H. Zhou, Q. Chen, Y. Liu, N. De Marco, Y. Yang, Improved air stability of perovskite solar cells via solution-processed metal oxide transport layers. Nat. Nanotechnol. 11, 75-81 (2016).doi:10.1038/nnano.2015.230 Medline

19. K. Domanski, J. P. Correa-Baena, N. Mine, M. K. Nazeeruddin, A. Abate, M. Saliba, W. Tress, A. Hagfeldt, M. Grätzel, Not all that glitters is gold: Metal-migrationinduced degradation in perovskite solar cells. ACS Nano 10, 6306-6314 (2016).doi:10.1021/acsnano.6b02613 Medline

20. X. Li, M. I. Dar, C. Yi, J. Luo, M. Tschumi, S. M. Zakeeruddin, M. K. Nazeeruddin, H. Han, M. Grätzel, Improved performance and stability of perovskite solar cells by crystal crosslinking with alkylphosphonic acid $\omega$-ammonium chlorides. Nat. Chem. 7, 703-711 (2015).doi:10.1038/nchem.2324 Medline

21. A. Mei, X. Li, L. Liu, Z. Ku, T. Liu, Y. Rong, M. Xu, M. Hu, J. Chen, Y. Yang, M. Grätzel, H. Han, A hole-conductor-free, fully printable mesoscopic perovskite solar cell with high stability. Science 345, 295-298 (2014).doi:10.1126/science.1254763 Medline

22. L. Zhang, T. Liu, L. Liu, M. Hu, Y. Yang, A. Mei, H. Han, The effect of carbon counter electrodes on fully printable mesoscopic perovskite solar cells. J. Mater. Chem. A 3, 9165-9170 (2015). doi:10.1039/C4TA04647A

23. W. Li, W. Zhang, S. Van Reenen, R. J. Sutton, J. Fan, A. A. Haghighirad, M. B. Johnston, L. Wang, H. J. Snaith, Enhanced UV-light stability of planar heterojunction perovskite solar cells with caesium bromide interface modification. Energy Environ. Sci. 9, 490-498 (2016). doi:10.1039/C5EE03522H

24. Materials and methods are available as supplementary materials on Science Online.

25. F. Bella, G. Leftheriotis, G. Griffini, G. Syrrokostas, S. Turri, M. Grätzel, C. Gerbaldi, A new design paradigm for smart windows: Photocurable polymers for quasi-solid photoelectrochromic devices with excellent long-term stability under real outdoor operating conditions. Adv. Funct. Mater. 26, 1127-1137 (2016). doi:10.1002/adfm.201503762

26. L. R. Wilson, B. S. Richards, Measurement method for photoluminescent quantum yields of fluorescent organic dyes in polymethyl methacrylate for luminescent solar concentrators. Appl. Opt. 48, 212-220 (2009).doi:10.1364/A0.48.000212 Medline

27. D. Bi, W. Tress, M. I. Dar, P. Gao, J. Luo, C. Renevier, K. Schenk, A. Abate, F. Giordano, J. P. Correa Baena, J.-D. Decoppet, S. M. Zakeeruddin, M. K. Nazeeruddin, M. Grätzel, A. Hagfeldt, Efficient luminescent solar cells based on tailored mixed-cation perovskites. Sci. Adv. 2, e1501170 (2016).doi:10.1126/sciadv.1501170 Medline

28. F. Giordano, A. Abate, J. P. Correa Baena, M. Saliba, T. Matsui, S. H. Im, S. M. Zakeeruddin, M. K. Nazeeruddin, A. Hagfeldt, M. Graetzel, Enhanced electronic properties in mesoporous $\mathrm{TiO}_{2}$ via lithium doping for high-efficiency perovskite solar cells. Nat. Commun. 7, 10379 (2016).doi:10.1038/ncomms10379 Medline

29. D. Liu, T. L. Kelly, Perovskite solar cells with a planar heterojunction structure prepared using room-temperature solution processing techniques. Nat. Photonics 8, 133-138 (2014). doi:10.1038/nphoton.2013.342

30. J.-H. Im, I.-H. Jang, N. Pellet, M. Grätzel, N.-G. Park, Growth of $\mathrm{CH}_{3} \mathrm{NH}_{3} \mathrm{Pbl}_{3}$ cuboids with controlled size for high-efficiency perovskite solar cells. Nat. Nanotechnol. 9, 927-932 (2014).doi:10.1038/nnano.2014.181 Medline

31. G. Griffini, M. Levi, S. Turri, Novel crosslinked host matrices based on fluorinated polymers for long-term durability in thin-film luminescent solar concentrators. Sol. Energy Mater. Sol. Cells 118, 36-42 (2013). doi:10.1016/..solmat.2013.05.041

32. G. Griffini, M. Levi, S. Turri, Novel high-durability luminescent solar concentrators based on fluoropolymer coatings. Prog. Org. Coat. 77, 528-536 (2014) doi:10.1016/j.porgcoat.2013.11.016

33. II Meteo; http://www.ilmeteo.it/meteo/Torino (accessed June 2016).

34. G. Griffini, F. Bella, F. Nisic, C. Dragonetti, D. Roberto, M. Levi, R. Bongiovanni, S. Turri, Multifunctional luminescent down-shifting fluoropolymer coatings: A straightforward strategy to improve the UV-light harvesting ability and long-term outdoor stability of organic dye-sensitized solar cells. Adv. Energy Mater. 5 , 1401312 (2015). doi:10.1002/aenm.201401312

35. C. Haines, M. Chen, K. P. Ghiggino, The effect of perylene diimide aggregation on the light collection efficiency of luminescent concentrators. Sol. Energy Mater Sol. Cells 105, 287-292 (2012). doi:10.1016/j.solmat.2012.06.030

36. F. Bella, G. Griffini, M. Gerosa, S. Turri, R. Bongiovanni, Performance and stability improvements for dye-sensitized solar cells in the presence of luminescent coatings. J. Power Sources 283, 195-203 (2015). doi:10.1016/j.jpowsour.2015.02.105

37. H. Yoo, J. Yang, A. Yousef, M. R. Wasielewski, D. Kim, Excimer formation dynamics of intramolecular $\pi$-stacked perylenediimides probed by singlemolecule fluorescence spectroscopy. J. Am. Chem. Soc. 132, 3939-3944 (2010).doi:10.1021/ja910724x Medline

38. G. Griffini, M. Levi, S. Turri, Thin-film luminescent solar concentrators: A device study towards rational design. Renew. Energy 78, 288-294 (2015) doi:10.1016/i.renene.2015.01.009

39. R. O. Al-Kaysi, T. Sang Ahn, A. M. Müller, C. J. Bardeen, The photophysical properties of chromophores at high (100 mM and above) concentrations in polymers and as neat solids. Phys. Chem. Chem. Phys. 8, 3453-3459 (2006).doi:10.1039/B605925B Medline 
40. J. A. Christians, P. A. Miranda Herrera, P. V. Kamat, Transformation of the excited state and photovoltaic efficiency of $\mathrm{CH}_{3} \mathrm{NH}_{3} \mathrm{Pbl}_{3}$ perovskite upon controlled exposure to humidified air. J. Am. Chem. Soc. 137, 1530-1538 (2015).doi:10.1021/ja511132a Medline

\section{ACKNOWLEDGMENTS}

All data used in this study are included in the main text and in the supplementary materials.

\section{SUPPLEMENTARY MATERIALS}

www.sciencemag.org/cgi/content/full/science.aah4046/DC1

Materials and Methods

Supplementary Text Sections 1 to 7

Figs. S1 to S8

References (34-40)

21 June 2016; accepted 20 September 2016

Published online 29 September 2016

10.1126/science.aah4046 
A

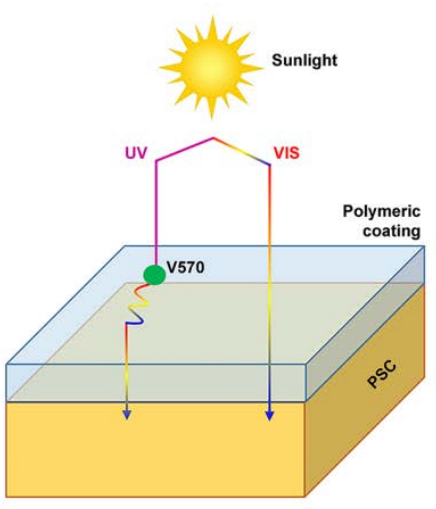

C

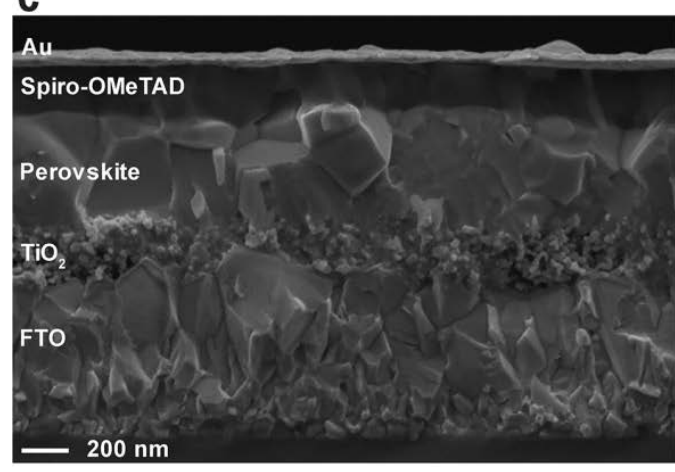

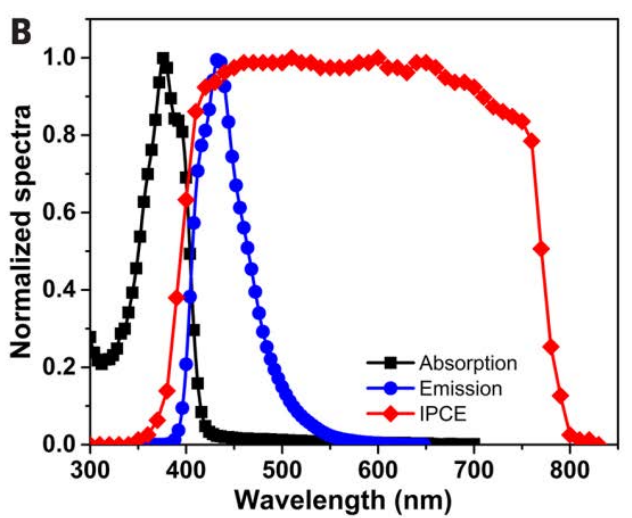

D

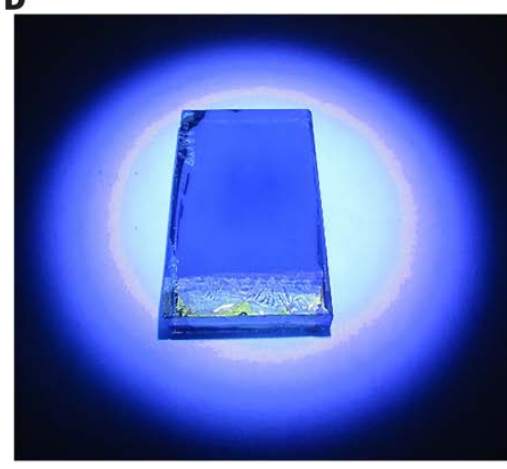

Fig. 1. LDS-PSC integrated system. (A) Scheme of the UV-coating operating principle. (B) Normalized absorption and emission spectra of V570-doped UV-coating compared to the IPCE response of the PSC devices under study. (C) Cross-sectional FESEM image of the PSC device before coating deposition. (D) Digital photograph of a PSC bearing the UV-coating when exposed to UV light. 

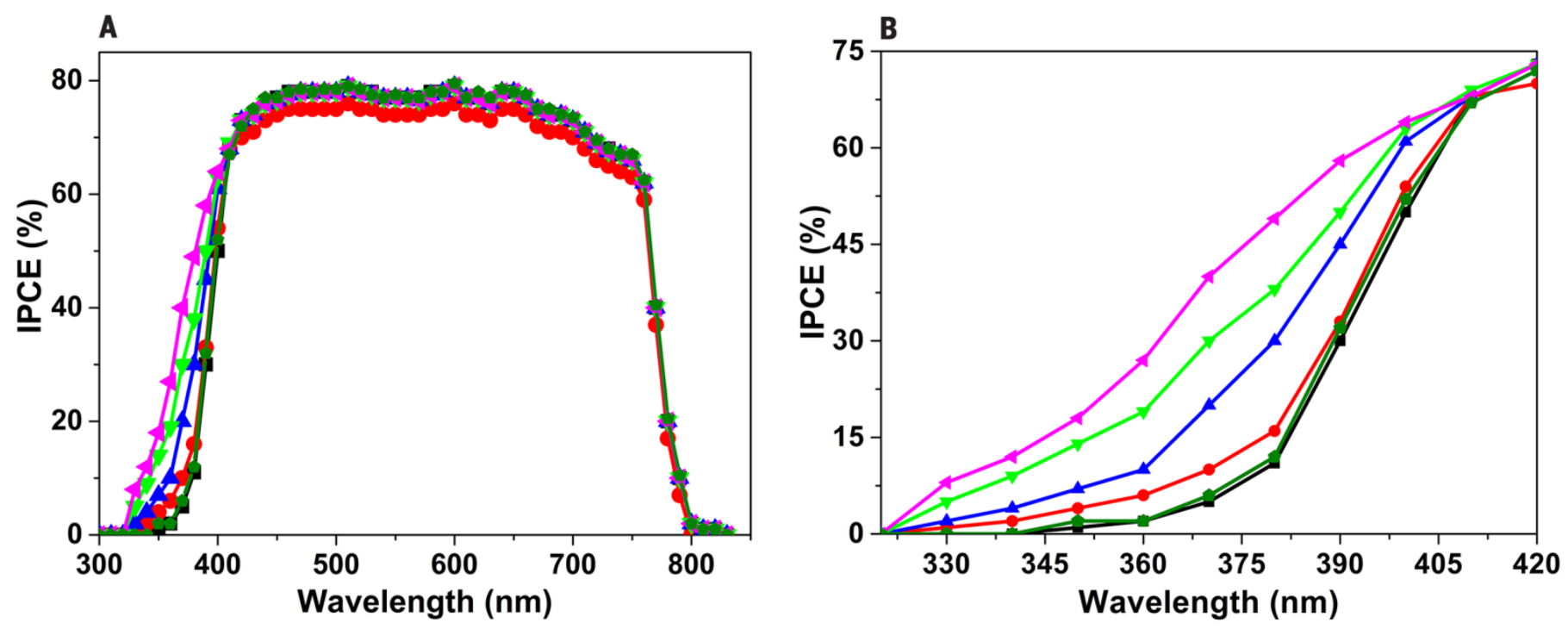

V570 content (wt\%): $\longrightarrow$ Uncoated $\rightarrow 0 \longrightarrow 0.5 \multimap 1.0 \multimap 1.5 \leftarrow 2.0$

Fig. 2. IPCE curves for PSCs. (A) Cells were coated with the LDS fluoropolymeric layer loaded with different amounts (0 to 2 wt\%) of V570. (B) Detail of IPCE curves for illumination below $420 \mathrm{~nm}$. Mask area $=0.16 \mathrm{~cm}^{2}$. 

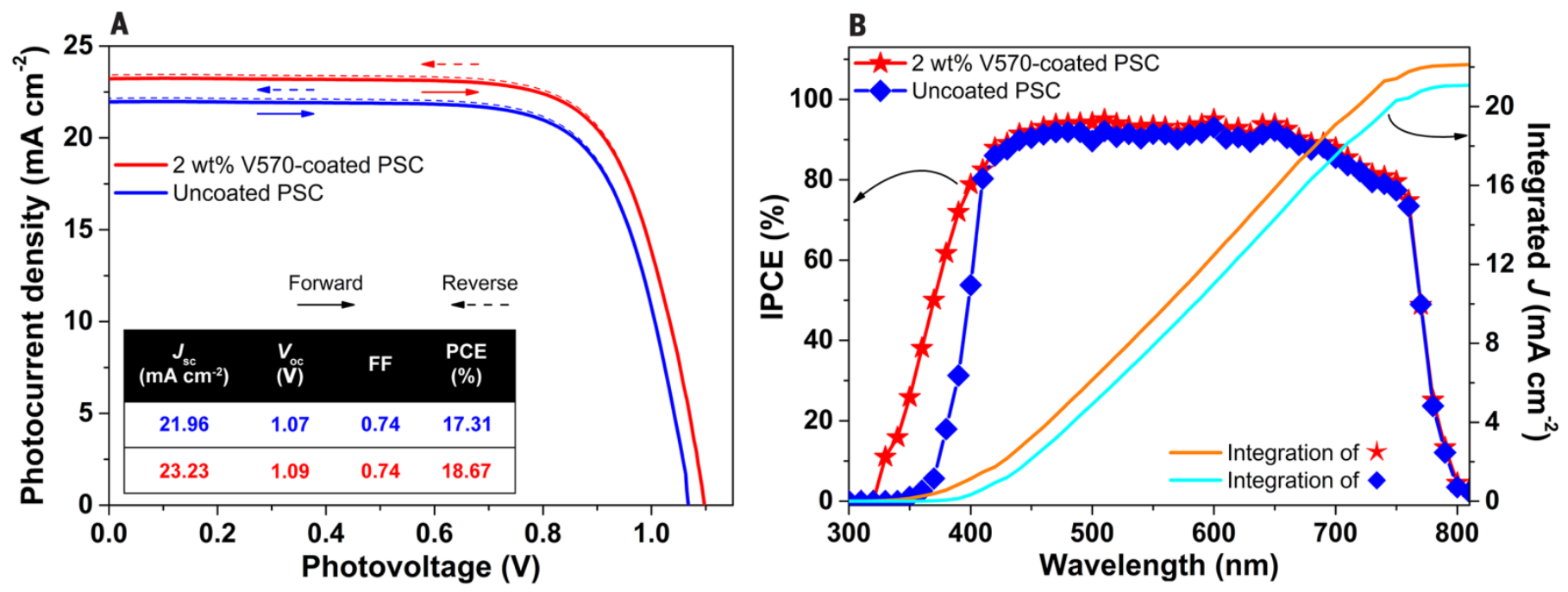

Fig. 3. Photovoltaic characterization of the best device. (A) J-V curves ( 1 sun, $A M 1.5 G, 5 \mathrm{mV} \mathrm{s}^{-1}$ ) for a highly efficient PSC before and after coating with the optimized LDS fluoropolymeric layer (2 wt\% V570). Dotted lines represent the reverse scan. (B) IPCE curves of the same PSCs. The integration of the product of the AM1.5G photon flux with the IPCE spectrum is also shown for coated and uncoated devices. 

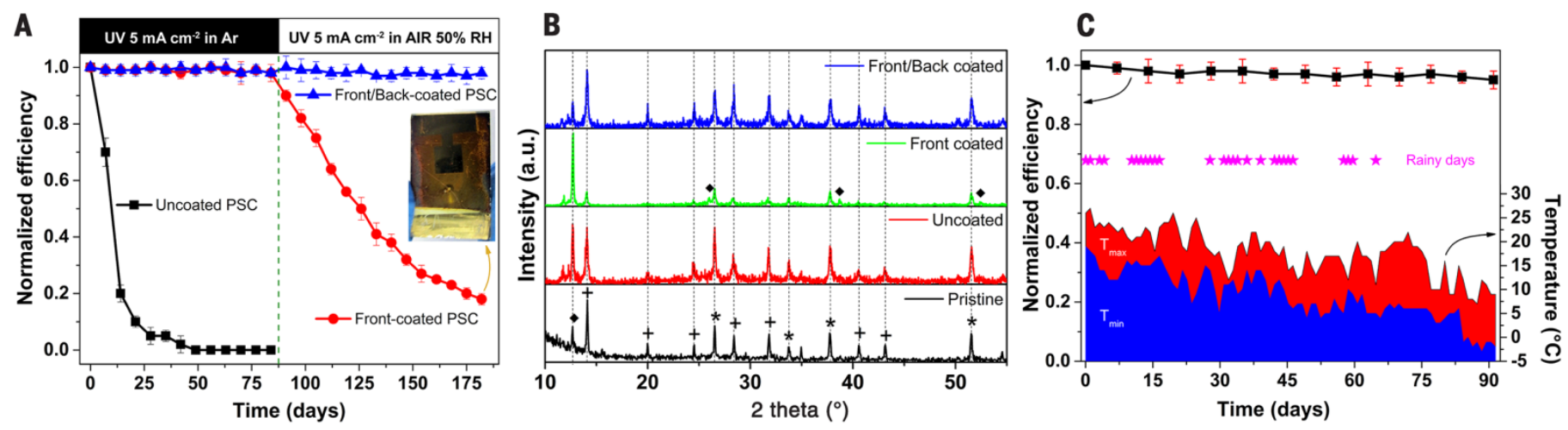

Fig. 4. Aging of LDS-PSC integrated system. (A) Results of the aging test on the three series of PSCs: uncoated, front-coated (i.e., luminescent fluorinated coating on the front side), and front/back coated (i.e., front side coated with the luminescent fluorophore and back contact coated with the moisture-resistant fluoropolymeric layer). During the first 3 months, PSCs were kept under Ar atmosphere, while in the next 3 months under air at 50\% RH, in both cases under continuous UV irradiation. PCE was measured once a week. A digital photograph of a front-coated solar cell at the end of the test is also shown. Further details are given in fig. S1A and section 5 in the supplementary materials. (B) XRD patterns of both uncoated and (front and front/back) coated PSC devices after the 6 months aging test. For comparison purposes, the XRD pattern of the pristine uncoated PSC system is also shown. Asterisks, crosses, and diamonds denote the main signals ascribed to FTO, perovskite, and $\mathrm{Pbl}_{2}$, respectively. (C) Results of the aging test on front/back coated devices left for three months on the terrace of the Politecnico di Torino building in Turin (Italy), thus experiencing real outdoor operating conditions. PCE was measured once a week. Further details are given in fig. S1B and section 7 in the supplementary materials. 
Table 1. Photovoltaic parameters of PSCs coated with the fluoropolymeric layer laden with different amounts (0-3 wt\%) of V570. Average values for uncoated devices are also shown for comparison purposes. Each experimental condition was reproduced five times on different devices; solar cells were tested under 1 sun, $A M 1.5 G$, at a scan rate of $5 \mathrm{mV} \mathrm{s}^{-1}$ and with a mask area of $0.16 \mathrm{~cm}^{2}$. In addition to the $J_{\mathrm{sc}}$ trend described in the text, a slight variation of $V_{o c}$ values can also be appreciated, scaling logarithmically with $J_{\mathrm{sc}}$ in accordance with the photodiode equation, i.e., $V_{o c}=k T q^{-1} \ln \left(J_{s c} J_{0}^{-1}+1\right)$.

\begin{tabular}{cccccc}
\hline $\begin{array}{c}\text { V570 } \\
(\mathbf{w t \%})\end{array}$ & $\begin{array}{c}\boldsymbol{J}_{\text {sc }} \\
\left(\mathbf{m A ~ c m} \mathbf{~ c m}^{-2}\right)\end{array}$ & $\begin{array}{c}\boldsymbol{V}_{\text {oc }} \\
(\mathbf{V})\end{array}$ & $\mathbf{F F}$ & $\begin{array}{c}\text { PCE } \\
(\%)\end{array}$ & $\begin{array}{c}\Delta \text { PCE } \\
(\%)\end{array}$ \\
\hline Uncoated & $19.20 \pm 0.05$ & $1.120 \pm 0.003$ & $0.72 \pm 0.01$ & 15.48 & 0 \\
\hline 0 & $18.14 \pm 0.05$ & $1.108 \pm 0.003$ & $0.72 \pm 0.01$ & 14.47 & -6.52 \\
\hline 0.5 & $18.52 \pm 0.04$ & $1.111 \pm 0.002$ & $0.73 \pm 0.01$ & 15.02 & -3.54 \\
\hline 1 & $19.37 \pm 0.06$ & $1.123 \pm 0.003$ & $0.72 \pm 0.01$ & 15.66 & +0.89 \\
\hline 1.5 & $19.90 \pm 0.05$ & $1.133 \pm 0.003$ & $0.72 \pm 0.01$ & 16.23 & +3.65 \\
\hline 2 & $20.31 \pm 0.04$ & $1.142 \pm 0.002$ & $0.73 \pm 0.01$ & 16.93 & +5.78 \\
\hline 2.5 & $20.20 \pm 0.06$ & $1.137 \pm 0.003$ & $0.72 \pm 0.01$ & 16.54 & +5.21 \\
\hline 3 & $20.11 \pm 0.08$ & $1.134 \pm 0.004$ & $0.73 \pm 0.01$ & 16.65 & +4.74 \\
\hline
\end{tabular}

